\title{
Identification and characterization of catalase genes in Eleusine coracana under abiotic stresses
}

\author{
S. SINGH ${ }^{1,2}$, R. CHOPPERLA ${ }^{1}$, S. KHAN ${ }^{2}$, N. REDDY ${ }^{3}$, J.C. PADARIA ${ }^{1}$, and A.U. SOLANKE ${ }^{*}$ \\ ICAR-National Institute for Plant Biotechnology, Pusa Campus, New Delhi 110012, India ${ }^{1}$ \\ Department of Bioscience and Biotechnology, Banasthali University, Banasthali, Rajasthan 304022, India ${ }^{2}$ \\ All India Coordinated Research Project on Small Millets, ICAR, GKVK, Bangalore 560065, India ${ }^{3}$
}

\begin{abstract}
Reactive oxygen species (ROS) are byproducts of metabolic processes such as respiration and photosynthesis in plants. Production of ROS leads to rapid cell damage, and plants developed a complex system of enzymatic and non-enzymatic antioxidants to scavenge these ROS. Catalase is an important enzyme, which plays a key role in elimination of toxic effects of hydrogen peroxide and plays a major role as an antioxidant. When characterizing heat responsive genes in finger millet (Eleusine coracana L.) using a suppression subtractive hybridization $(\mathrm{SSH})$ library, we isolated two catalase genes and named them as EcCATA1 and EcCATB1. The lengths of the EcCATA1 and EcCATB1 open reading frames were 1482 and $1426 \mathrm{bp}$, respectively. We characterized these genes under different abiotic stresses and in different tissues. The tissue wise expression revealed that EcCATA1 expression was higher in leaves whereas EcCATB1 expression was higher in roots than in other organs. Under stress conditions, the expression of EcCATAl was highest under salt stress followed by mannitol treatment. In the case of $E c C A T B 1$, the highest expression was observed under mannitol treatment followed by cold and dehydration. We also studied expression of both the genes under heat stress in different finger millet genotypes and observed that expressions of these genes can be correlated with heat tolerance. For both the genes, a detailed computational investigation was also performed for understanding their structural properties and physicochemical characteristics. Overall, this is the first study to identify and characterize catalase genes from climate resilient finger millet crop.
\end{abstract}

Additional key words: finger millet, gene expression and cloning, heat, mannitol, reactive oxygen species, salinity.

\section{Introduction}

Finger millet [Eleusine coracana $($ L. $)$ Gaertn.] $(2 \mathrm{n}=4 \times=36)$ is a minor millet grown in the broad range of environmental conditions. This crop comprises $12 \%$ of the worldwide millet area. It is cultivated in over 25 countries of Asia and Africa as one of the major food sources (Gowda et al. 2000, Adhikari 2012) and it is an excellent resource of mineral nutrients like calcium, iron, phosphorus, and amino acids like methionine and lysine (Dida et al. 2008). Finger millet encompasses numerous salient characteristics such as an inbreeding nature, short life cycle, and climate resilience (Kumar et al. 2016).

Aerobic metabolism generates reactive oxygen species (ROS) as a by-product in plant cells. Their production increases when plants are subjected to biotic and abiotic stresses resulting into cell injury, DNA and RNA damage, lipid peroxidation, protein oxidation, and enzyme inhibition (Scandalios 1993, Miller et al. 2008). Oxygen toxicity is an intrinsic characteristics of aerobic life, as it has been supposed that $1 \%$ of the oxygen used by plants is altered to generate ROS (Asada 1992). Under control conditions, production and scavenging ROS remain in equilibrium. Increased activities of ROS scavenging enzymes have a high potential of plant metabolic regulations in a stressful environment (Chaitanya et al. 2002, Foyer and Noctor 2005). Plants have developed a complex antioxidant defense system, which is made of enzymes such as catalase, glutathione peroxidase, ascorbate peroxidase, superoxide dismutase, glutathione reductase, and peroxiredoxins. Among the ROS, $\mathrm{H}_{2} \mathrm{O}_{2}$ is a signaling molecule, but disproportionate formation of $\mathrm{H}_{2} \mathrm{O}_{2}$ has been shown to

Submitted 11 June 2018, last revision 4 February 2019, accepted 6 February 2019.

Abbreviations: EcCATA1 and EcCATB1 - Eleusine coracana catalase A1 and B1; GRAVY - grand average of hydropathicity; qPCR quantitative polymerase chain reaction; ROS - reactive oxygen species; SSH - suppression subtractive hybridization.

Acknowledgements: We acknowledge the All India Coordinated Research Project on Small Millets, ICAR, GKVK, Bangalore-560065 for providing seed material, and the National Innovations in Climate Resilient Agriculture Project (NICRA), a flagship project of Indian Council of Agricultural Research (ICAR), New Delhi, India for providing financial support.

* Corresponding author; e-mail: amolsgene@gmail.com 
be cytotoxic outcoming in hypersensitive cell death. A low production of $\mathrm{H}_{2} \mathrm{O}_{2}$ obstructs the progression of cell cycle and acts as a developmental sign for the beginning of secondary wall differentiation. Hence, the production of $\mathrm{H}_{2} \mathrm{O}_{2}$ must be specifically controlled by plants (Ushio-Fukai 2006). Certainly, antioxidant activity regulation in the plant is a key for adaption to environmental stresses, as well as a crucial aspect in regulating cellular signal transduction (Veal et al. 2007). Characterization of the antioxidant reaction may provide better understanding the nature of photo-oxidative processes activated by a specific stress.

Catalase (1.11.1.6) was the first antioxidant enzyme identified and characterized. Catalase is a heme containing tetrameric ubiquitous enzyme, which catalyzes the division of two $\mathrm{H}_{2} \mathrm{O}_{2}$ molecules into oxygen and water. There are many different types of enzymes present in plants which degrade $\mathrm{H}_{2} \mathrm{O}_{2}$, still, catalases are unique because they do not need cellular reducing equivalent (Scandalios et al. 1997). Three catalase genes are identified in most angiosperm species, e.g., in tobacco Class I catalases are expressed in photosynthetic tissues and are controlled by irradiance; Class II catalases are expressed mostly in vascular tissues whereas Class III catalases are abundant in young seedlings and seeds (Willekens et al. 1995). In general, the importance of catalase can be either in its straight antioxidant activity or in its capability to trigger signal transduction pathways that require $\mathrm{H}_{2} \mathrm{O}_{2}$ as a messenger (Willekens et al. 1994a, Anderson et al. 1998). Earlier, an increased expression of wheat catalase in rice shows an enhanced tolerance to low temperature stress in transgenic rice (Matsumura et al. 2002). Catalase from Suaeda salsa provides resistance against oxidative stress in transgenic rice (Zhao and Zhang 2006).

A high temperature triggers a broad range of plant reactions along with an increase in ROS and up-regulation of their scavengers. Gene expression study in response to heat stress provides a definite appraise of antioxidant gene activation beside enzyme activity. Therefore, the aim of the present study was to characterize highly upregulated catalase genes identified in our heat stress suppression subtractive hybridization (SSH) library. In this study, we isolated and characterized two catalase genes EcCATA1 and $E c C A T B 1$ with respect to high-temperature treatment and also under other abiotic stresses to better utilize in the crop improvement.

\section{Materials and methods}

Plants and treatments: The finger millet [Eleusine coracana (L.) Gaertn.] cultivar MR1 was used in this study. Along with it, 16 other genotypes were also used for expression analysis of EcCAT genes under heat stress. Seeds of all the genotypes were sown in Soilrite. Seedlings were grown under a $24 \pm 1{ }^{\circ} \mathrm{C}$ temperature, a $60 \%$ relative humidity, a 16-h photoperiod, and an irradiance of $510 \mu \mathrm{mol} \mathrm{m} \mathrm{m}^{-2} \mathrm{~s}^{-1}$. The seedlings (14-d-old) were exposed to $42{ }^{\circ} \mathrm{C}$ and collected after 2,4 , and $24 \mathrm{~h}$ of heat treatment. Seedlings grown at $24 \pm 1{ }^{\circ} \mathrm{C}$ were used as a control. Three biological replicates were used for all the experiments. Further, MR1 seedlings were exposed to the following abiotic stresses: seedlings were placed in Petri plates having filter papers saturated with $10 \mathrm{~cm}^{3}$ of $200 \mathrm{mM} \mathrm{NaCl}, 10 \%(\mathrm{~m} / \mathrm{v})$ polyethylene glycol $\left(\mathrm{PEG}_{6000}\right)$, or $200 \mathrm{mM}$ mannitol. For heat and cold treatments, seedlings were subjected to incubation at $42{ }^{\circ} \mathrm{C}$ and $4{ }^{\circ} \mathrm{C}$, respectively. Samples were collected after different time intervals as described Chopperla et al. (2017). For each time point, around 10 seedlings were harvested, pooled, and frozen immediately in liquid nitrogen and placed at $-80{ }^{\circ} \mathrm{C}$ until further study. For tissue expression analysis, leaves, roots, stems, panicles, and germinated seeds were collected along with whole seedlings.

Isolation of RNA and cDNA preparation: Total RNA was extracted from finger millet seedlings using a Spectrum ${ }^{\mathrm{TM}}$ plant total RNA kit (Sigma Aldrich, St. Louis, USA) according to the user manual. Genomic DNA contamination was eliminated using On column DNase digestion (Sigma Aldrich). Concentration and quality of total RNA preparation was determined with a spectrophotometer ND-1000 (Thermo Fisher Scientific, San Jose, USA) and $1 \%(\mathrm{~m} / \mathrm{v})$ agarose/formaldehyde gel electrophoresis. The cDNA was synthesized using $1 \mu \mathrm{g}$ of total RNA isolated with a High Capacity $c D N A R T$ kit (Applied Biosystems, Foster City, USA) according to the user manual. Random hexamer and oligo(dT) primers were used in the reverse transcription reactions. The resultant cDNAs were diluted 5-fold and from this dilution, $1 \mathrm{~mm}^{3}$ was used as a template for quatitative polymerase chain (qPCR) reaction.

Sequence analysis: We designed full-length gene specific primers using a Primer3 online tool (http://bioinfo.ut.ee/ primer3-0.4.0/) to amplify EcCAT genes using heat treated cDNA (Table 1 Suppl.). After PCR, the amplified products were electrophoretically separated on an agarose gel $(1.2 \%)$ and eluted with an QIAquick gel extraction kit (Qiagen, Valencia, USA). The extracted products were cloned into a pGEM-T easy vector (Promega, Madison, USA). Positive colonies were screened through gene specific colony PCR and subjected to plasmid isolation. The $E c o$ RI was used to release the insert, and these clones were confirmed by Sanger sequencing. As the information of finger millet catalase protein is unavailable, we calculated its physiochemical properties using a ProtParam tool of the ExPASy server (Wilkins et al. 1999). For multiple sequence alignment analysis, amino acid sequences of EcCAT proteins with other homolog catalases from different plant species were aligned using the ClustalX2.1 software. A phylogenetic tree was generated using the MEGA 7.0 software (http://www.megasoftware.net/).

Protein modeling and structure validation: The protein 3D structure of EcCAT proteins was modeled through the I-TASSER server (http://zhang.bioinformatics.ku.edu/ITASSER/; Jianyi et al. 2015). Structural models were constructed using an appropriate Protein database bank through an iterative fragment assembly method followed 
by a functional prediction with known proteins from the functional databases. The generated models were further assessed using the volume area dihedral angle reporter (VADAR; Willard et al. 2003) and the structure analysis and verification server (SAVES; http://nihserver.mbi.ucla. edu/SAVES/), which harbors different analysis tools like PROCHECK and ProFunc (Laskowski et al. 1993, 2005), ERRAT (Colovos and Yeates 1993) and Verify3D (Bowie et al. 1991). The VADAR 1.5 program (http://vadar. wishartlab.com/) gives qualitative information on modeled protein, which includes mean hydrogen bond energies and hydrogen bonding distance, accessible surface area, steric quality, and excluded volume including solvation free energy. ProSA was used for the analysis of $Z$ scores and energy plots (Sippl 1993).

Expression analysis: The qPCR was carried out with primers of EcCATA1 and EcCATB1 (Table 1 Suppl.) using the diluted cDNA as a template. The PCR was carried out with a $1 \times$ SYBR mix (Stratagene, California, USA) using Light cycler $480 I I$ (Roche, Indiana, USA) with preheating at $95{ }^{\circ} \mathrm{C}$ for $5 \mathrm{~min}$ proceeded with 40 cycles of $95^{\circ} \mathrm{C}$ for $30 \mathrm{~s}, 60^{\circ} \mathrm{C}$ for $30 \mathrm{~s}$, and $72^{\circ} \mathrm{C}$ for $30 \mathrm{~s}$. A PCR amplification specificity was analyzed at the end of amplification by melt curve analysis. To normalize the quantity of cDNA in each reaction, the EcUbiquitin gene from finger millet was amplified as an internal reference gene. The amplified PCR products were analyzed on a $1 \%(\mathrm{~m} / \mathrm{v})$ agarose gel to confirm an expected size. Three replicates were used for each cDNA sample, and the data were analyzed for relative fold expression as per Kanakachari et al. (2016).

Statistical analysis: For each experiment, three biological replicates, each containing at least three technical replicates, were used. Data sets were calculated as means \pm SEs and one-way analysis of variance was used to determine the significance of differences between the samples. For comparison of different means, the Tukey honestly significat difference (HSD) test was used at $\alpha=0.05$.

\section{Results}

Two cDNA clones of catalase, highly represented in the SSH cDNA library generated by us from heat treated finger millet seedlings, were used in this analysis. Genespecific primers were designed and PCR was carried out. The products were further cloned and sequenced. On the basis of their homology with respective rice catalases, names of the genes were designated as EcCATAl and $E c C A T B 1$. Finally, both the sequences were submitted to NCBI (an accession number of EcCATA1: MH822444 and of EcCATB1: MH822445).

Physicochemical characterizations of EcCATA1 and EcCATB1 are extremely important to show properties like
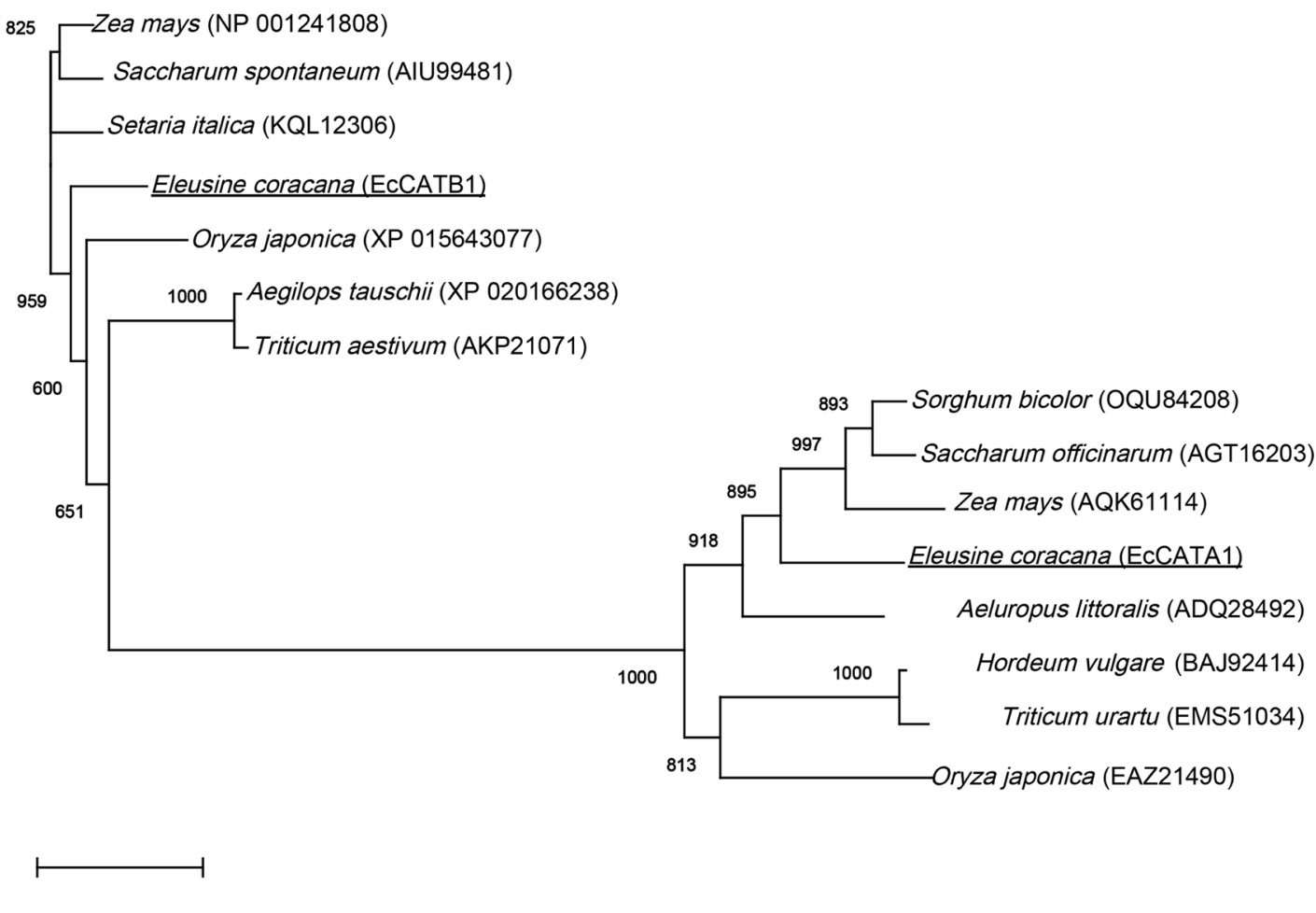

0.05

Fig. 1 Phylogenetic analysis of EcCATA1 and EcCATB1 with catalase proteins from some related species. All proteins were initially aligned using ClustalW and were then used for phylogenetic analysis using the MEGA 7.0 software (http://www. megasoftware.net). A phylogenetic tree was constructed using the neighbor-joining method. Acession numbers generated in the study are underlined. The numbers on the individual node signify bootstrap values from 1000 replicates. A multiple alignment used for phylogeny of EcCATA1 and EcCATB1 is given in Fig. 1 Suppl. 


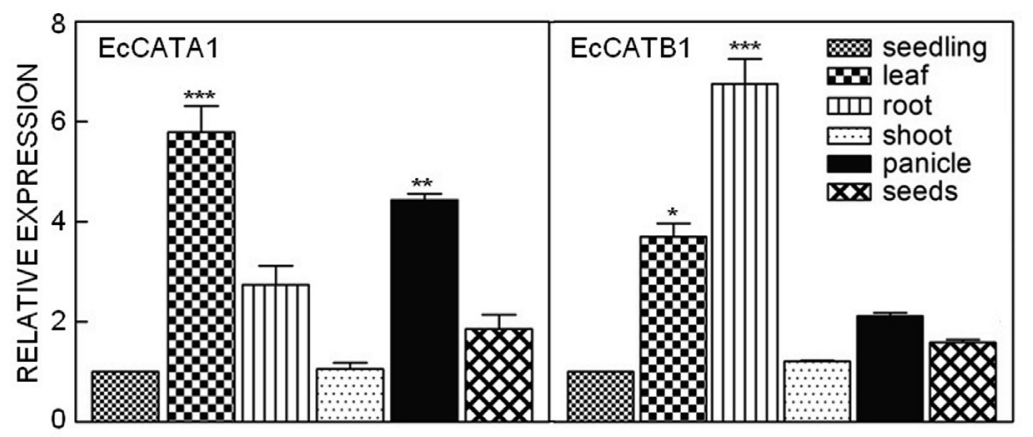

Fig. 2. Expression analysis of EcCATA1 and EcCATB1 in different tissues of finger millet determined by quantitative PCR analysis of 14-d-old seedlings. Means \pm SEs, $n=3$, asterisks indicate significant differences at $P<0.05$ (the Student $t$-test).

the number of amino acid residues, theoretical isoelectric points, the number of atoms, coefficients of absorption, instability indices, molecular mass, aliphatic indices, atomic composition, and grand average of hydropathicity (GRAVY) (Table 2 Suppl.). The total numbers of amino acid residues in EcCATA1 and EcCATB1 were 493 and 472, respectively. Putative molecular masses of EcCATA1 and EcCATB1 determined in silico were 56.67 and 54.49 $\mathrm{kDa}$, and isoelectric points 6.54 and 6.91 , respectively. Similarly, predictive subcellular localizations of these proteins were examined. Analysis with the WoLF PSORT program indicates that EcCATA1 was localized in cytoplasm and EcCATB1 was localized in peroxisomes. Aliphatic indices for these catalases were 69.61 (EcCATA1) and 74.77 (EcCATB1) suggesting a higher thermostability of these proteins. Charges at $\mathrm{pH} 7$ for EcCATA1 and EcCATB1 were -3.01 and -0.3, respectively, which means both proteins were acidic in nature. Stability indices for EcCATA1 and EcCATB1 were 35.16 and 27.83 , respectively. As values of instability index for both proteins were lower than 40, these are stable proteins. The GRAVY value of EcCATA1 was -0.550 and of EcCATB1 -0.480 . This lower GRAVY values show the establishment of a better interaction between the protein and water.

The two EcCATgenes had a significant sequence identity between themselves at the nucleic acid level (70\%) with a $75 \%$ query coverage, and at the deduced amino acid level $70 \%$ with $100 \%$ query coverage. The pairwise sequence alignments of EcCATA1 and EcCATB1 protein sequences with other catalases show the presence of conserved active site residues (Fig. 1 Suppl.). The BLASTP searches against the GenBank database indicate that EcCATA1 shared a $93 \%$ similarity with catalase from Sorghum bicolor (accession number OQU 84207), 92 \% with Saccharum cultivars (accession number AGT 16203), $91 \%$ with Aeluropus littoralis (accession number ADQ 28492), and $90 \%$ with Zea mays (accession number AQK_61114). The EcCATB1 shared a $92 \%$ similarity with Setaria italica (accession number KQL 12306), Zea mays (accession number NP_001241808), and Sacchrum spontaneum (accession number AIU_99481). When a phylogenetic tree was prepared to compare the EcCAT genes with foxtail millet, sugarcane, rice, maize, and wheat catalase genes, two clear clusters of EcCATA1 and EcCATB1 were observed (Fig. 1). Furthermore, a conserved domain database was used for identification of conserved domains in both the proteins. The EcCATA1 protein contained four domains: 1) catalase (18 - 398 amino acids), 2) catalaserel (catalase-related immuno-responsive; 78 - 114 amino acids), 3) tRNA (Ile) lysidine synthetase - Tils (Tils substrate binding domain; 440 - 484 amino acids), and 4) histone-like nucleoid structuring dependent expression A (425 - 487 amino acids) whereas EcCATB1 contained only two domains: 1) catalase (18 - 386 amino acids) and 2) catalase-rel (403 - 466 amino acids). A detailed description of the different domains and the structures of EcCATA1 and EcCATB1 are shown in Fig. 1 Suppl.

A graphical representation of the percentages of sheets, helices, strands, and turns of both EcCATA1 and EcCATB1 is given in Fig. 2 Suppl. EcCATA1 showed $43 \beta$-turns compared with 47 in EcCATB1. EcCATA1 had $3 \beta$-sheets, 12 strands, $18 \gamma$-turns, and 20 helices whereas EcCATB1 had 2 sheets, 11 strands, 13- $\gamma$ turns, and 18 helices identified by ProFunc. The alignment of EcCATA1 and EcCATB1 sequences with selected templates having different query coverage scores, identity scores, and Z-scores were predicted in Figs. 3 and 4 Suppl., respectively. Out of three models predicted, one best model of EcCATA1 (C-Score $=1.79)$ and EcCATB1 $(\mathrm{C}-\mathrm{Score}=1.89)$ (Fig. 3 and 4 Suppl.) were selected to validate the structure and further consideration. The Ramachandran plot was generated via the PROCHECK server to calculate the existence of residues present in different regions. The allowed regions for molecular fragment replacement of EcCATA1 and EcCATB1 demonstrated 76.8 and $78.0 \%$ residues, respectively whereas 2.1 and $0.5 \%$ residues were presented in disallowed regions (Table 3 and 4 Suppl.). Evaluation of EcCATA1 and EcCATB1 with ProSA-Web revealed the Z-score values as -8.52 and -8.12 , respectively, which suggests that both structures had native features and near to a crystal structure (Fig. 3 and 4 Suppl.). ERRAT calculated overall quality factor scores for non-bonded atomic interaction and scored to the tune of 87.474 and 92.358 in EcCATA1 and EcCATB1, respectively. The mean residue volume of the EcCATA1 and EcCATB1 models were 1.414 and $1.426 \mu \mathrm{m}$, respectively, which shows a good packing density of these proteins.

Results of qPCR with gene-specific primers shows a relative transcript abundance of EcCATA1 in finger millet 


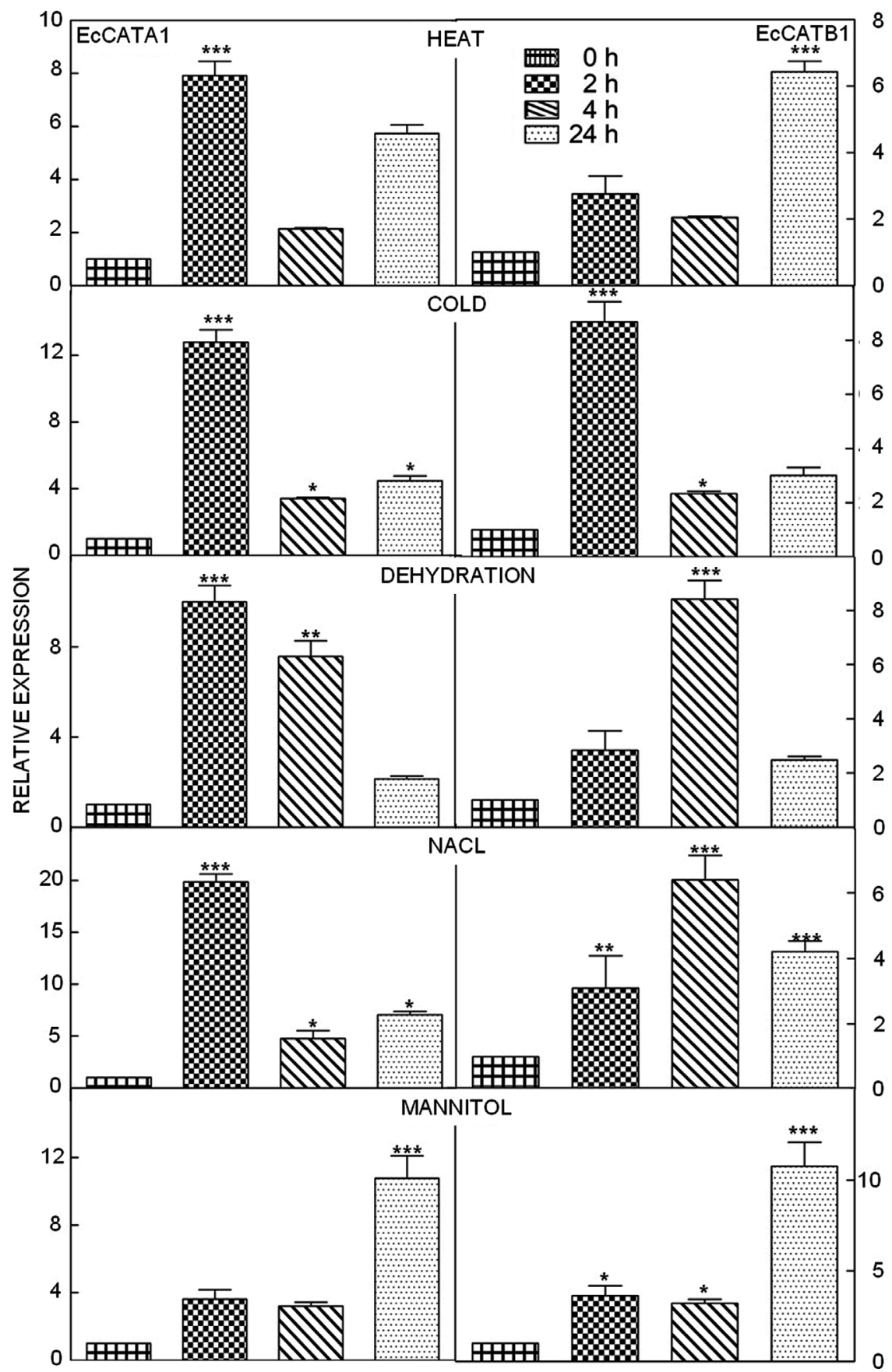

Fig. 3. Expressions of EcCATA1 and EcCATB1 determined by quantitative PCR in finger millet under different abiotic stresses in 14-d-old seedlings after 2, 4, and $24 \mathrm{~h}$. Means $\pm \mathrm{SEs}, n=3$, asterisks indicate significant differences at $P<0.05$ (the Student $t$-test).

leaves and panicles whereas in the case of EcCATB1, a maximum relative expression was observed in roots followed by leaves (Fig. 2). Under the abiotic stresses, the maximum expression of EcCATAl was observed under $\mathrm{NaCl}$ followed by cold, PEG, and heat at $2 \mathrm{~h}$ (Fig. 3). Only under the mannitol stress, the maximum abundance was observed after $24 \mathrm{~h}$. For EcCATB1 a relative abundance of the transcript increased after $2 \mathrm{~h}$ of the cold stress, after $4 \mathrm{~h}$ of the PEG and $\mathrm{NaCl}$ stresses and after $24 \mathrm{~h}$ under the mannitol and heat stresses (Fig. 3).

Expression analysis of EcCATA1 and EcCATB1 in 16 finger millet genotypes was carried out using real-time PCR. Expression of EcCATA1 changed from 0.28- to 10-folds under the heat stress in the studied cultivars (Fig. 4). The results show that expression of EcCATA1 increased mostly at $2 \mathrm{~h}$ under the stress conditions in all the cultivars. Along with up-regulation at $2 \mathrm{~h}$, the maximum expression of EcCATA1 was observed at $24 \mathrm{~h}$ in the PES110 and PR202 genotypes whereas the lowest expression was observed in KOPN330 and GN5. Transcription of EcCATB1 changed from 0.18 - to 8 -folds in the studied cultivars (Fig. 5). The results show that expression of EcCATB1 was maximum 


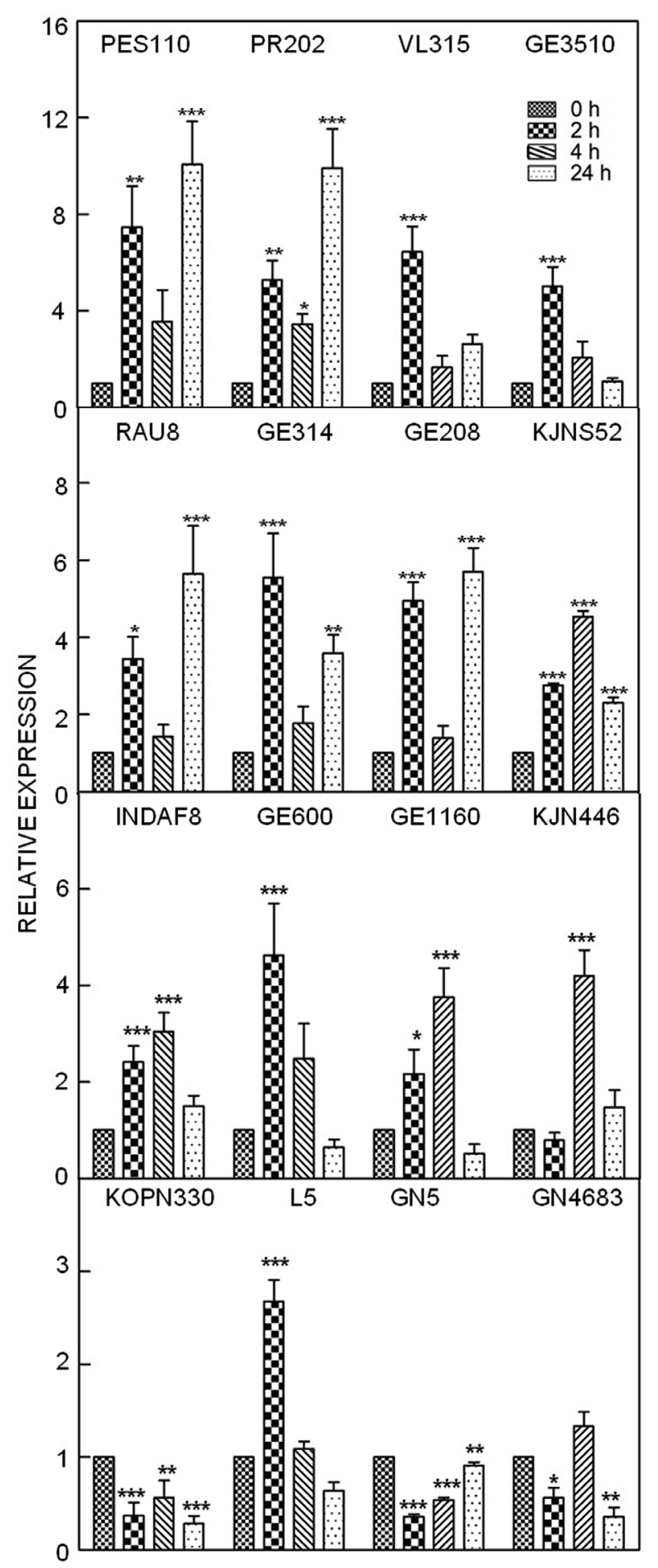

Fig. 4. Expression of EcCATA1 determined by quantitative PCR analysis in 16 finger millet genotypes after heat stress at $42{ }^{\circ} \mathrm{C}$ for different time periods in 14-d-old seedlings. Means \pm SEs, $n=3$, asterisks indicate significant differences at $P<0.05$ (the Student $t$-test).

at $24 \mathrm{~h}$ in most of the genotypes. In few genotypes, the maximum expression was observed at $2 \mathrm{~h}$ of the heat stress. The highest expression was detected in the PES110

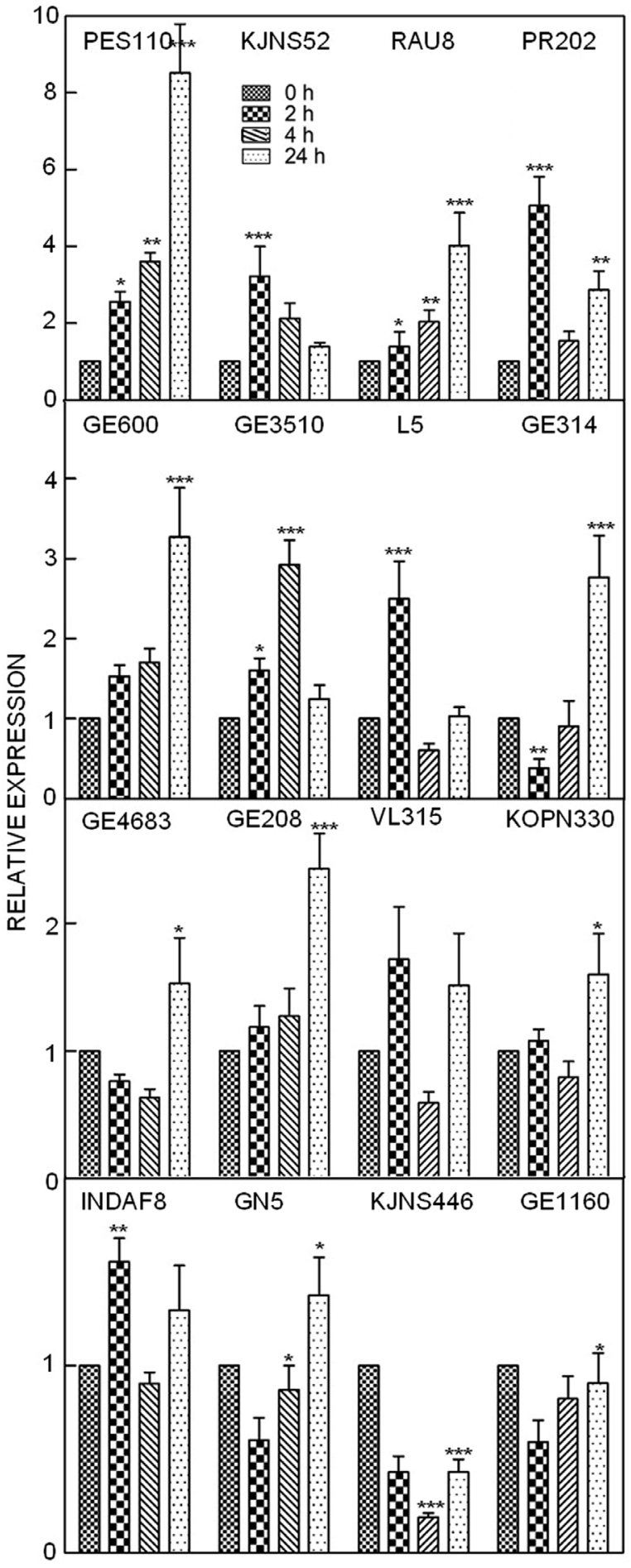

Fig. 5. Expression of EcCATB1 determined by quantitative PCR analysis in 16 finger millet genotypes after heat stress at $42{ }^{\circ} \mathrm{C}$ for different time periods in 14- d-old seedlings. Means \pm SEs, $n=3$, asterisks indicate significant differences at $P<0.05$ (the Student $t$-test).

genotype with an 8.5 -fold increase at $24 \mathrm{~h}$ whereas the least expression was observed in the genotype KJNS446 at $4 \mathrm{~h}$ of the heat stress. 


\section{Discussion}

The principal propose of this study was to isolate and characterize the essential ROS scavenging catalase genes (EcCATA1 and EcCATB1) from finger millet and to analyze the expression pattern of these genes under different abiotic stresses and plant developmental stages to confirm their role in abiotic stress tolerance of finger millet. We obtained two full-length catalase genes from the SSH library prepared from the heat-treated finger millet seedlings. We observed that catalase members of finger millet contained distinctive domains specific to the catalase and catalase immune responsive family (Cat-rel), which is the major class of ROS scavenging antioxidants (Mhamdi et al. 2010). Based on the crystal structure of catalase, a successful 3D structural model was constructed for both the EcCATA1 and EcCATB1 proteins by using homology modeling method. In our study, with the aid of molecular dynamics and mechanics methods, we achieved the final protein model of EcCATA1 and EcCATB1, and further these models were evaluated by standard programs, like SAVES and VADAR, which proved that the final refined protein models are reliable.

The expression analysis revealed that EcCATA1 was abundant in leaves as compared with panicles and roots whereas negligible in shoots and seeds. EcCATB1 was equally expressed in panicles, shoots, and seeds whereas the maximum expression was observed in roots and leaves. Similarly, a higher expression of the CAT2 gene was observed in root tissue of cucurbit species under heat stress (Ara et al. 2013). Several previous studies are in agreement with our findings that both EcCATA1 and EcCATB1 mRNAs are highly abundant in leaves (Willekens et al. 1994b, Esaka et al. 1997). Therefore, it is indicative that EcCATA1 and EcCATB1 are involved in scavenging photorespiratory $\mathrm{H}_{2} \mathrm{O}_{2}$ as suggested by Willekens et al. (1994b).

Catalase genes are differently expressed not only in developmental stages but also are responsive to numerous environmental signals, e.g., in brocoli, rice, and chickpea (Lin et al. 2010, Nahakpam and Shah 2011, Kaur et al. 2013). The activity and expression of catalases also trigger in various stress conditions, for example at $\mathrm{NaCl}$, drought, chilling, osmotic stress, UV-B, $\mathrm{O}_{3}$, and $\mathrm{SO}_{2}$ (Mittler et al. 1994, Willekens et al. 1994a, Guan and Scandalios 2000, Luna et al. 2005, Yong et al. 2017). Similarly, in the present study, both EcCATA1 and EcCATB1 showed a high mRNA abundance under the $\mathrm{NaCl}$, mannitol, dehydration, and cold stresses. Several studies reported expression of catalase genes in response to heat stress in maize, Arabidopsis, tobacco, mustard, and cabbage (Willekens et al. 1994a, McClung 1997, Scandalios et al. 1997, 2000, Dat et al. 1998, Lin et al. 2010). Herein, we report the response of the finger millet catalase gene expression to heat stress and show the differential expression profile: an initial expression of EcCATA1 restored within $2 \mathrm{~h}$ of the stress, further reduction was observed at $4 \mathrm{~h}$, and again expression increased at $24 \mathrm{~h}$ in the heat tolerant genotypes. In contrast, EcCATA1 expression did not increase in the susceptible genotypes, or in some genotypes, it increased only slightly. This may be a result of changes in photorespiration rate, which has been noticed at temperature stress (Berry and Bjorkman 1980). It is possible that the initial heat shock led to a rapid decline in EcCATB1 transcripts in the heat sensitive finger millet genotypes similarly to $N$. plumbaginifolia Cat2 transcripts, which decreases during heat stress (Willekens et al. 1994b). This is the first study of isolation and characterization of finger millet catalase genes under different abiotic stress conditions.

\section{References}

Adhikari, R.K.: Economics of finger millet (Eleusine coracana L.) production and marketing in periurban area of Pokhara valley of Nepal. - J. dev. Agr. Econ. 4: 151-157, 2012.

Anderson, M., Chen, Z., Klessig, D.F.: Possible involvement of lipid peroxidation in salicylic acid mediated induction of PR-1 gene expression. - Phytochemistry 47: 555-566, 1998.

Ara, N., Nakkanong, K., Lv, W., Yang, J., Hu, Z., Zhang, M.: Antioxidant enzymatic activities and gene expression associated with heat tolerance in the stems and roots of two cucurbit species ("Cucurbita maxima" and "Cucurbita moschata") and their interspecific inbred line "Maxchata". Int. J. mol. Sci. 14: 24008-24028, 2013.

Asada, K.: Ascorbate peroxidase a hydrogen scavenging enzyme in plants. - Physiol. Plant. 85: 235-241, 1992.

Berry, J., Bjorkman, O.: Photosynthetic response and adaptation to temperature in higher plants. - Ann. Rev. Plant Physiol. 31: 491-543, 1980.

Bowie, J.U., Luthy, R., Eisenberg, D.: A method to identify protein sequences that fold into a known three-dimensional structure. - Science 12: 164-170, 1991.

Chaitanya, K.V., Sundar, D., Masilamani, S., Reddy, A.R.: Variation in heat stress-induced antioxidant enzyme activities among three mulberry cultivars. - Plant Growth Regul. 36: 175-180, 2002.

Chopperla, R., Singh, S., Mohanty, S., Reddy, N., Padaria, J.C., Solanke, A.U.: Isolation and expression analysis of EcbZIP17 from different finger millet genotypes shows conserved nature of the gene. - 3 Biotech. 7: 342, 2017.

Colovos, C., Yeates, T.O.: Verification of protein structures: patterns of non-bonded atomic interactions. - Protein Sci. 2: 1511-1519, 1993.

Dat, J.F., Lopez-Delgado, H., Foyer, C.H., Scott, I.M.: Parallel changes in $\mathrm{H}_{2} \mathrm{O}_{2}$ and catalase during thermotolerance induced by salicylic acid or heat acclimation in mustard seedlings. Plant Physiol. 116: 1351-1357, 1998.

Dida, M., Wanyera, N., Harrison Dunn, M., Bennetzen, J., Devos, K.: Population structure and diversity in finger millet (Eleusine coracana) germplasm. - Trop. Plant Biol. 1: 131141, 2008.

Esaka, M., Yamada, N., Kitabayashi, M., Setoguchi, Y., Tsugeki, R., Kondo, M., Nishimura, M.: cDNA cloning and differential gene expression of three catalases in pumpkin. - Plant mol. Biol. 33: 141-155, 1997.

Foyer, C.H., Noctor, G.: Redox homeostasis and antioxidant signaling: a metabolic interface between stress perception and physiological responses. - Plant Cell 17: 1866-1875, 2005.

Gowda, B.T., Halaswamy, B.H., Seetharam, A., Virk, D.S., Witcombe, J.R.: Participatory approach in varietal improvement: a case study in finger millet in India. - Curr. Sci. 10: 366-368, 2000.

Guan, L.M., Scandalios, J.G.: Catalase transcript accumulation 
in response to dehydration and osmotic stress in leaves of maize viviparous mutants. - Redox Rep. 5: 377-383, 2000.

Jianyi, Y., Yang, Z.: I-TASSER server: new development for protein structure and function predictions. - Nucl. Acids Res. 43: W174-W181, 2015.

Kanakachari, M., Solanke, A.U., Prabhakaran, N., Ahmad, I., Dhandapani, G., Jayabalan, N., Kumar, P.A.: Evaluation of suitable reference genes for normalization of qPCR gene expression studies in brinjal (Solanum melongena L.) during fruit developmental stages. - Appl. Biochem. Biotechnol. 178: 433-450, 2016.

Kaur, K., Kaur, N., Gupta, A.K., Singh, I.: Exploration of the antioxidative defense system to characterize chickpea genotypes showing differential response towards water deficit conditions. - Plant Growth Regul. 70: 49-60, 2013.

Kumar, A., Metwal, M., Kaur, S., Gupta, A.K., Puranik, S., Singh, S., Singh, M., Gupta, S., Babu, B.K., Sood, S., Yadav, R.: Nutraceutical value of finger millet [Eleusine coracana (L.) Gaertn.], and their improvement using omics approaches. - Front. Plant Sci. 7: 934, 2016.

Laskowski, R.A., MacArthur, M.W., Moss, D.S., Thornton, J.M.: PROCHECK: a program to check the stereochemical quality of protein structures. - J. appl. Crystallogr. 26: 283-291, 1993.

Laskowski, R.A., Watson, J.D., Thornton, J.M.: ProFunc: a server for predicting protein function from 3D structure. Nucl. Acid. Res.33: W89-W93, 2005.

Lin, K.H., Huang, H.C., Lin, C.Y.: Cloning, expression and physiological analysis of broccoli catalase gene and Chinese cabbage ascorbate peroxidase gene under heat stress. - Plant Cell Rep. 29: 575-593, 2010.

Luna, C.M., Pastori, G.M., Driscoll, S., Groten, K., Bernard, S., Foyer, C.H.: Drought controls on $\mathrm{H}_{2} \mathrm{O}_{2}$ accumulation, catalase (CAT) activity and CAT gene expression in wheat. - J. exp. Bot. 56: 417-423, 2005.

Matsumura, T., Tabayashi, N., Kamagata, Y., Souma, C., Saruyama, H.: Wheat catalase expressed in transgenic rice can improve tolerance against low temperature stress. - Physiol. Plant. 116: 317-327, 2002.

McClung, C.R.: Regulation of catalases in Arabidopsis. - Free Rad. Biol. Med. 23: 489-496, 1997.

Mhamdi, A., Queval, G., Chaouch, S., Vanderauwera, S., Van, B.F., Noctor, G.: Catalase function in plants: a focus on Arabidopsis mutants as stress-mimic models. - J. exp. Bot. 61: 4197-4220, 2010.

Miller. G., Shulaev, V., Mittler, R.: Reactive oxygen signaling and abiotic stress. - Physiol. Plant. 133: 481-489, 2008.

Mittler, R., Zilinskas, B.A.: Regulation of pea cytosolic ascorbate peroxidase and other antioxidant enzymes during the progression of drought stress and following recovery from drought. - Plant J. 5: 397-405, 1994.

Nahakpam, S., Shah, K.: Expression of key antioxidant enzymes under combined effect of heat and cadmium toxicity in growing rice seedlings. - Plant Growth Regul. 63: 23-35, 2011.

Scandalios, J.G.: Oxygen stress and superoxide dismutases. Plant Physiol. 101: 7-12, 1993.

Scandalios, J.G., Acevedo, A., Ruzsa, S.: Catalase gene expression in response to chronic high temperature stress in maize. - Plant Sci. 156: 103-110, 2000.

Scandalios, J.G., Guan, L., Polidoros, A.N.: Catalases in plants: gene structure, properties, regulation, and expression. - Cold Spring Harbor Monograph Series 34: 343-406, 1997.

Sippl, M.J.: Recognition of errors in three-dimensional structures of proteins. - Proteins 17: 355-362, 1993.

Ushio-Fukai, M.: Localizing NADPH oxidase-derived ROS. Sci. STKE 349: re8, 2006.

Veal, E.A., Day, A.M., Morgan, B.A.: Hydrogen peroxide sensing and signaling. - Mol. Cells 26: 1-14, 2007.

Willard, L., Ranjan, A., Zhang, H., Monzavi, H., Boyko, R.F., Sykes, B.D., Wishart, D.S.: VADAR: a web server for quantitative evaluation of protein structure quality. - Nucl. Acids Res. 31: 3316-3319, 2003.

Willekens, H., Inzé, D., Van, M.M., Van, C.W.: Catalases in plants. - Mol. Breed. 1: 207-228, 1995.

Willekens, H., Langebartels, C., Tire, C., Van, M.M., Inze, D., Van, C.W.: Differential expression of catalase genes in Nicotiana plumbaginifolia (L.). - Proc. nat. Acad. Sci. USA. 91: 10450-10454, 1994a.

Willekens, H., Van, C.W., Van, M.M., Inze, D., Langebartels, C., Sandermann, Jr, H.: Ozone, sulfur dioxide, and ultraviolet B have similar effects on mRNA accumulation of antioxidant genes in Nicotiana plumbaginifolia L. - Plant Physiol. 106: 1007-1014, 1994b.

Wilkins, M.R., Gasteiger, E., Bairoch, A., Sanchez, J.C., Williams, K.L., Appel, R.D., Hochstrasser, D.F.: Protein identification and analysis tools in the ExPASy server. - Methods mol. Biol. 112: 531-552, 1999.

Yong, B., Wang, X., Xu, P., Zheng, H., Fei, X., Hong, Z., Ma, Q., Miao, Y., Yuan, X., Jiang, Y., Shao, H.: Isolation and abiotic stress resistance analyses of a catalase gene from Ipomoea batatas (L.) Lam. - BioMed. Res. Int. 6847532: 1-10, 2017.

Zhao, F., Zhang, H.: Salt and paraquat stress tolerance results from co-expression of the Suaeda salsa glutathione S-transferase and catalase in transgenic rice. - Plant Cell Tissue Organ Cult. 86: 349-358, 2006. 